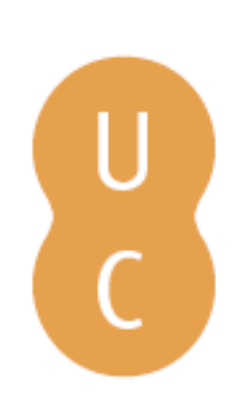

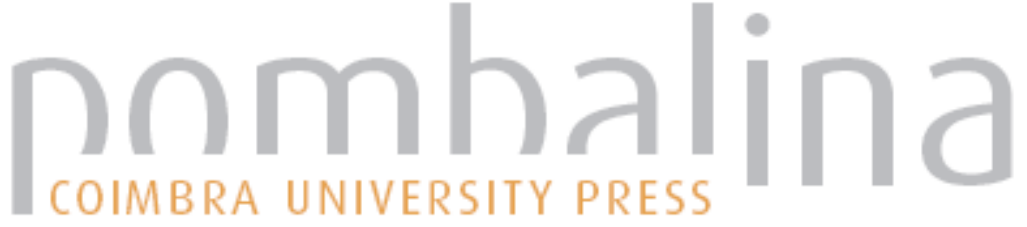

\section{Actividades de lazer em Roma}

Autor(es): Oliveira, Francisco de

Publicado por: Imprensa da Universidade de Coimbra

URL

persistente: $\quad$ URI:http://hdl.handle.net/10316.2/38371

DOI: $\quad$ DOI:http://dx.doi.org/10.14195/978-989-26-0371-1_9

Accessed : $\quad$ 26-Apr-2023 10:26:47

A navegação consulta e descarregamento dos títulos inseridos nas Bibliotecas Digitais UC Digitalis, UC Pombalina e UC Impactum, pressupõem a aceitação plena e sem reservas dos Termos e Condições de Uso destas Bibliotecas Digitais, disponíveis em https://digitalis.uc.pt/pt-pt/termos.

Conforme exposto nos referidos Termos e Condições de Uso, o descarregamento de títulos de acesso restrito requer uma licença válida de autorização devendo o utilizador aceder ao(s) documento(s) a partir de um endereço de IP da instituição detentora da supramencionada licença.

Ao utilizador é apenas permitido o descarregamento para uso pessoal, pelo que o emprego do(s) título(s) descarregado(s) para outro fim, designadamente comercial, carece de autorização do respetivo autor ou editor da obra.

Na medida em que todas as obras da UC Digitalis se encontram protegidas pelo Código do Direito de Autor e Direitos Conexos e demais legislação aplicável, toda a cópia, parcial ou total, deste documento, nos casos em que é legalmente admitida, deverá conter ou fazer-se acompanhar por este aviso.

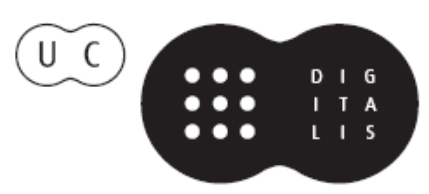


FRANCISCO DE OLIVEIRA

Coordenação

Ospírito Olímpico

no

novo milénio 


\section{ACTIVIDADES DE LAZER EM ROMA}

Francisco de Oliveir a Universidade de Coimbra

O termo ludus, com os verbos correspondentes, significa 'jogo, divertimento, divertir-se à custa de outrem, praticar desporto, lugar do jogo ou do desporto, escola'. O plural ludi especializou-se no sentido de 'festivais'.

Ora, como o próprio sentido etimológico parece indicar, um dos motivos, certamente mais prosaico, mas nem por isso menos verdadeiro, para a existência do jogo, é o divertimento, isto é, o prazer que nele se colhe.

E todas as idades procuravam esse prazer. As crianças, como ocupação do seu tempo, divertem-se em jogos variados: com animais (fig. I: Museu Capitolino), com carros de brincar, à bola, ao boxe, às cavalitas, ao arco (fig. 2: Museu do Vaticano).

Os adultos, para preencherem o seu ócio, também se entregam a actividades das quais não retiram qualquer utilidade imediata, mas que nem por isso são menos importantes, quer por ocuparem o tempo de lazer, quer por permitirem o convívio salutar com os parceiros de jogo: banquetes, pesca, mergulho, disco, bola, atletismo, hóquei (fig.3).

As próprias mulheres se exercitavam em jogos de dados, concursos de beleza musculação, (fig.4: mosaico de Piazza Armerina).

No caso dos adultos, o jogo pode constituir um meio de esquecer as fadigas da luta pela sobrevivência, um momento de repouso necessário e recuperador de energias, particularmente no termo de determinadas tarefas cíclicas, como as vindimas. Nesta medida, o jogo, como forma 
de ócio, decorre de uma necessidade fisiológica de repouso temporárioO.

Quanto aos jogos de natureza violenta, como o boxe, o dardo, a equitação, a luta livre, a dança, e especialmente a dança ritual, os jogos de gladiadores, pode ainda pensar-se que cumpririam determinadas funções: servir de preparação militar, dar saída legal às pulsões e instintos de violência e de agressividade, ou fornecer momentos de descompressão.

De resto, a ligação dos jogos às artes e momentos de guerra é bem conhecida das civilizações clássicas: recordemos os jogos em honra de Pátroclo, longamente descritos na llíada; cenas tantas vezes repetidas nos vasos gregos, como a de Aquiles a jogar aos dados com Ájax no intervalo dos combates; a utilização do Campo de Marte em Roma como lugar de treino e desporto(2); o conhecido Ludus ou Lusus Troiae, cerimónia romana em que dois esquadrões de jovens da alta sociedade, com idades entre os 12 e os 16 anos, evoluíam a cavalo, chegando a ser enquadrados pelos principes iuuentutis, destinados herdeiros do Império( $\left.{ }^{3}\right)$.

Esta função paramilitar dos jogos constitui já um aproveitamento utilitário do lazer.

Aos pedagogos também não passou despercebida a sua real importância formativa, como vemos em Aristóteles( $\left.{ }^{4}\right)$.

Outro aproveitamento decorre da consciência de que o jogo é, normalmente, uma actividade colectiva e social, com a consequente tendência para o Estado ou a colectividade organizarem jogos públicos ou estabelecerem ligação entre os jogos e as actividades políticas.

(0 Recordar, de Virgílio, os trechos de Geórgicas, 2.525-529; e de Eneida, 6.640-640-647, que nos mostra como, no próprio além, a actividade lúdica está presente; cf. Aristoteles, Política, 1337b.

(2) J. Gagé, La chute des Tarquins et le début de la république romaine, Paris, Payot, 1976, estabelece mesmo ligação entre a revolução que derrubou os Tarquinios e instaurou a República e as rivalidades entre grupos de jovens aristocratas que se treinavam em espaços diferentes.

(3) J. Balsdon 1969 327- 328.

(4) Política, 1335b, sobre a formação juvenil. 
Este facto está atestado desde cedo na Grécia, onde, bem cedo, ágora e teatro tinham uma ligação estreitai ${ }^{5}$ ).

Em Roma, a ligação entre política e jogos faz parte da lenda das origens, com o célebre Rapto das Sabinas, realizado aquando de festivais em honra de Consus (fig.5: forum de Roma, basílica Aemilia)

Algumas manifestações cívicas e religiosas romanas continham mesmo uma componente lúdica, como no caso das cerimónias dos Lupercos, que corriam à volta do Palatino; da festividade do October equus, a 15 de Outubro, onde os fiéis disputavam a cauda de um cavalo; ou do Regifugium, a 24 de Fevereiro, onde o sacerdote que presidia ao sacrifício, o rex sacrificulus, simulava uma fuga.

Este carácter religioso e cívico ajuda a explicar o facto de, em Roma, e originariamente na Grécia, a assistência aos ludi oficiais ser gratuita, sem prejuízo de se ter de arranjar bilhete para garantir lugar sentado.

Outro aspecto que desde cedo nos aparece, é a ligação dos jogos ao culto dos mortos, a qual já viria da Grécia, quer nos recordemos da célebre máscara mortuária de Agamémnon(6), quer atentemos nos homéricos jogos fúnebres em honra de Pátroclo, na llíada, quer nos fixemos na história do herói Adrasto.

Em Roma, acaso por influência dos Etruscos, que enriqueceram os seus túmulos com frescos cheios de referências a actividades de lazer, pelo menos desde o séc II aC os jogos aparecem como componente dos funerais dos aristocratas. Recordemos só dois exemplos marcantes: o dos jogos fúnebres em honra de Paulo Emílio, no ano de 160 aC, onde foram representadas as peças Os Dois Irmãos e a segunda versão de A Sogra de Terêncio; e o dos jogos fúnebres dados por Júlio César em honra de seu pai, com um paralelo na tradição literária romana, os jogos fúnebres em honra de Anquises, no livro $\mathrm{V}$ da Eneida de Virgílio.

(5) Ver F. Kolb, "Theaterpublikum, Volksversammlung und Gesellschaft in der griechischen Welt", Dioniso 59 345-351; e, para a temática da função política do teatro, os meus artigos citados na bibliografia.

(6) Estou a estabelecer um nexo, talvez ousado, com a utilização de máscara no teatro grego. 
Existiam também jogos privados e variados espectáculos de rua, com acrobatas, marionetas, ilusionistas e teatro popular (fig.6: Vaticano, Museu Pio Clementino)(7).

Mas ao nosso ponto de vista interessam sobretudo os festivais oficiais, que se realizavam sob a responsabilidade de um ou mais magistrados, nessa função chamado(s) editor(es): os edis da plebe nos Jogos Plebei e Ceriales; os edis curuis nos jogos Romani, A^lego/enses e Floralia; o pretor urbano nos Apollinares.

Estes seis grandes festivais republicanos, onde as componentes atléticas se ligam às cénicas, tinham duas características marcantes: a primeira, o facto de serem organizados por magistrados ainda em fase de competição política por magistraturas do cursus honorum, o que levará à politização e utilização partidária e pessoal dos festivais; a segunda, a circunstância de se bifurcarem em duas categorias: os festivais incumbidos a magistrados essencialmente aristocratas e os jogos organizados por magistrados plebeus.

Esta dupla via de organização traduz um sábio equilíbrio social e político de poderes, correspondente à existência de um Estado que costumamos chamar patrício- plebeu.

Nos jogos praticavam-se várias modalidades, que, por brevidade, só em parte enunciarei.

As corridas de cavalos realizavam-se no Circo Máximo (fig.7: Museo delia Civiltà Romana), que chegou a ultrapassar os 250.000 espectadores(8), congregando, assim, num momento de lazer e coesão cívica, a quase totalidade dos habitantes de Roma. Digo habitantes, não digo cidadãos, para mostrar que, embora excluídos das assembleias políticas onde só eram admitidos cidadãos, os restantes habitantes de Roma podiam estar ao lado daqueles em determinados momentos de importância política, cívica e religiosa.

I14 As corridas de cavalos remontariam, segundo os Romanos, ao tempo de Rómulo, e a equitação, como forma tradicional de treino militar, era praticada pela juventude romana no Campo de Marte.

(7)Cf.J. Balsdon 1969 287- 288.

(8) Sobre a capacidade do Circo Máximo e as corridas, ver J. Balsdon 1969265 SS 314 ss. e 324; R. Auguet 1970151 ss.; o circo era um lugar de encontro social, com mistura de homens e mulheres, dando ocasião a encontros de apaixonados. 
No início, tratar-se-ia de corridas de cavalos, mais tarde de corridas de carros. A sua importância decresce à medida que surgem as outras formas de espectáculo.

Tal como na Etrúria, as corridas de cavalos teriam uma ligação originária com as divindades infernais ou com cultos predominantemente agrários.

Existiam várias especialidades, onde se destacava a corrida de carros puxados por quatro cavalos, ou quadriga (fig.8: mosaico dos aurigas, Museo Nacional de Arte Romano de Mérida). O sinal de partida (missus) era dado com um pano branco ou mappa. A colocação era feita por tiragem à sorte e havia apostas. A corrida consistia em 7 voltas ao circuito, no total de 8.400 metros, com o seu eixo central ou spina, cujo contorno era manobra muito perigosa (fig.9: Foligno, Pinacoteca Communale). O cocheiros dos carros que se voltavam perigosamente (naufragium) eram reanimados com uma poção de excrementos de javali, que funcionava como poderoso analgésico( $\left.{ }^{(}\right)$.

A corrida era disputada normalmente por quatro escuderias, cada uma representada por sua cor, pela qual os Romanos se deixavam obcecar: branca ou albata e vermelha ou russata, as mais antigas; verde ou prasina e azul ou veneta, as mais recentes, que haveriam de absorver as duas primeiras.

As sedes destas escuderias eram autênticos clubes, como a Maison des Chevaux em Cartago, e as corridas propriamente ditas eram um evento sociak ${ }^{10}$ ).

Nos primeiros anos do Império os azuis estão mais ligados à aristocracia: são seus adeptos Vitélio e Caracala; os verdes ao povo: a estes aderem os imperadores Caligula e Nero, que podemos enquadrar na chamada tirania demagógica.

Os combates de gladiadores ou munera (fig. 10: Museu de Paestum) são jogos de origem provavelmente etrusca que chegaram a Roma em

(9) Cf. Plin.Nat.28.237- 238.

(O)J. Balsdon 1969 esp. 321. 
264 aC, directamente ou através da Campânia, como rito funerário da aristocracia, sendo mais tarde introduzidos nos jogos oficiais, assumindo um papel central na vida públicaC ').

Fazer lutar prisioneiros em frente da sepultura seria o sucedâneo de um rito primitivo, em que esses mesmos prisioneiros eram imolados sobre o túmulo de grandes guerreiros, na crença de que o sangue derramado sobre o morto constituía uma espécie de garantia de continuidade de vida.

Os gladiadores eram especializados, e o grande interesse do jogo era ver como se enfrentavam duas armas ou duas tácticas diferentes de combatei12), segundo normas rígidas: um retiarius contra um secutor ou myrmillo (fig. I I: mosaico do Museu de Augst); um Samnita contra um Trácioí13).

O gladiador aprendia a matar (fig. 12: Museu Arqueológico de Dorres) como aprendia a morrer (fig. 13: Gaulês moribundo, do Museu Capitolino). Aos olhos do público, um gladiador derrotado que tivessse combatido corajosamente tinha mais oportunidades de ser missus 'poupado' que um hesitante e cobarde.

As uenationes ou caçadas revelam um interesse dos Romanos pelos animais também atestado na lenda das origens e na prática da caça enquanto actividade de lazer (fig. 14: camafeu). Têm a ver, ainda, com um traço distintivo, pouco conhecido do mundo grego, que é considerar os animais como um duplicado do comportamento humano.

(") J. Balsdon 1969 248-249; J. C. Edmondson 1996 69- 112.

(12) Samnita ou secutor fortemente armado, contra um Trácio armado à ligeira; retiarius vs. secutor. Vêm a surgir outras numerosas especialidades, até par evitar a monotonia ou redobrar o interesse: essedarii, que combatem num carro; equites, a cavalo e com lança; dimacharii, sem escudo, mas uma espada em cada mão; laqueatores armados de uma espécie de laço; andabates, de olhos vendados; paegniarii, para os intermédios paródicos; combates sine missione, onde não há stantes missi, pois o combate é até à morte; noxii ad gladium ludi damnati, verdadeiras execuções em massa: o último sobrevivente ou era degolado ou guardado para um outro espectáculo.

(13) R. Auguet 197086. 
Aparecidas tardiamente, as uenationes eram uma forma espectacular de executar condenados, por exemplo cristãos, como no caso de Daniel atirado aos leões (fig. 15: relicário do séc. IV, Lião).

Mas, no circo, para além da espectacularidade e do estrondoso número de animais (fig. 16: Museu de El Jem), havia um especial condimento para o gosto romano, o exótico, com elefantes, avestruzes (fig. 17: mosaico de Piazza Armerina), aves raras, ursos, leões e leopardos, caçados vivos e transportados das mais longínquas terras do Império e até da India (elefantes) e do Cáucaso (tigres), num comércio tão intenso que levou à extinção de espécies (fig. 18: mosaico de Piazza Armerina)(14).

O valor cultural das uenationes é especialmente evidente se recordarmos que elas estão especialmente ligadas aos jogos triunfais, onde representavam, para a grande massa dos espectadores, a ilustração do conhecimento geográfico do Império.

As naumaquias, nascidas no tempo de César (46 aC), eram batalhas navais, por vezes sob a forma de reconstituição histórica(15), que levavam à morte verdadeiros exércitos de gladiadores e prisioneiros. Não terão sobrevivido, todavia, para além do séc. I dC.

Para as realizar, Augusto construiu um lago artificial de 536 por 357m, na base do Janiculo; Cláudio recorreu ao Lago Fucino; Nero edificou o seu anfiteatro de modo a receber naumaquias, graças à possibilidade de enchimento da arena, processo que foi seguido em numerosos anfiteatros espalhados por todo o Império, como é o caso de MéridaO6).

(14) A estatística do número de animais mortos é aterradora: cf. J. Balsdon 1969 307- 308. $\mathrm{Na}$ província, era regra contentarem-se com as feras locais; não assim em Roma, onde o Imperador é obrigado a criar verdadeiros parques de animais, os uiuaria, além de reservar para si o monopólio do comércio de leões e elefantes.

(IS) J. Balsdon 1969329 cita, em 46 aC, Tírios contra Egípcios; em 2 aC, Atenienses contra Persas; em 80 dC, Córcira contra Corinto; Atenas contra Siracusa.

(16)J. Balsdon 1969 328- 329. 
Em Roma, o teatro assume várias formas:

teatro pré- literário e popular, como a atelana e o mimo; e teatro literário, isto é, com texto escrito, como o pantomimo, a fabulo togata a fabula palliata, nas suas variantes de comédia e de tragédia (fig. 19: Museu Capitolino).

No geral, os ludi scaenici ou jogos teatrais foram admitidos como uma parte dos outros festivais ${ }^{7}$ ).

De início, o teatro seria representado em lugares temporários e em praças públicas, havendo notícia de representações nos bairros ou uici de Roma até meados do séc. I aC. O primeiro edifício permanente, em pedra dura, foi o Teatro de Pompeu, datado de $55 \mathrm{aC}$., seguido pelo de Marcelo (fig.20: reconstituição do Museo delia Civiltà Romana).

A disposição dos espectadores, na sequência da / ex Roscia theatralis de $67 \mathrm{aC}$, depois completada com a lex Papia Poppaea de $9 \mathrm{dC}$, era ai selectiva: senadores na Orquestra; equites nas 14 primeiras filas; mulheres e desqualificados na summa cauea, por vezes em forma de pórtico.

Esta disposição selectiva era um sinal evidente de politização, na medida em que distinguia ou segregava os estratos populacionais de acordo com a hierarquia social. Ao fazê-lo, permitia que qualquer manifestação de um desses grupos pudesse ser claramente identificável, dando voz a estratos sociais que não podiam pronunciar-se colectivamente noutras circunstâncias(18).

Estou, com isto, de certo modo a contradizer opiniões como a de P. Veyne ou de Auguet, que acusam os jogos, na época imperial, de contribuírem para a despolitização das massasO99).

(17)J. Balsdon 1969 248: "So on fifty-six of the seventy-seven days of regular public games at the time of Augustus, on 101 out of 177 days in the mid-third century A.D., any Roman who could secure a seat sought his entertainment in the theatre".

(18) C. Nicolet 1976460 enumera as ocasiões em que se podia manifestar uma opinião pública fora das assembleias institucionais:

"...les funérailles, les triomphes, les

représentations théâtrales ou les combats de gladiateurs ..." (cf. p.480). D. Potter 1996 apresenta uma bela exposição sobre a importância, formas e fórmulas de manifestação política no teatro.

(19) O próprio título da conhecida obra de P. Veyne, 'O pão e o circo', sugere uma visão negativa da iniciativa política popular; por sua vez, escreve R. Auguet 1970 178: "Plus que d'une politisation du cirque, les faits mentionnés témoignent d'une dépolitisation des masses 
Várias das razões apontadas, desde a ligação entre a vertente religiosa e a vertente cívica dos jogos enquanto promotores de coesão sociaK* 20 ); à circunstância de serem organizados e parcialmente pagos por magistrados ávidos de ascensão política(21); ao facto de se dar neles a proximidade entre os líderes políticos e a população (fig.21 : obelisco de Karnak, Constantinopla), e à disposição selectiva dos espectadores, justificam o que Balsdon escreve: "...não havia lugar mais apropriado para manifestações eficazes do que os jogos públicos e os espectáculos"(22).

$\mathrm{Na}$ Grécia, essa politização tem logo a ver com a diferença de festivais: carácter pan-helénico nas Grandes Dionísias; reserva para a política doméstica nas Leneiasí23).

Em Roma, no período republicano, a questão tem sido relacionada fortemente com o facto de o editor concorrer às eleições seguintes, no esquema do cursus honorum; para o período imperial, fala-se em histrionismo do poder, sendo Nero o exemplo mais citado(24).

De facto, por um lado, o espectáculo dava ao povo ocasião de manifestar os seus sentimentos, favoráveis ou hostis, para com altas personalidades - senadores, editor; por outro, constituía um meio de atrair popularidade e de ganhar votos ou simpatia(25).

De entre as manifestações violentas, com desacatos da ordem pública, recordemos a refrega entre Pompeianos e habitantes de Nucéria, no ano de 59 dC (fig.22: fresco do Museu Arqueológico de Nápoles), e a do ano 190 d.C., quando, após a sétima volta, um grupo de crianças guiadas por uma rapariga se lançou na pista para protestar

- nourrie par l'État et protégée aux frontières para des généraux dont elles ont pris I'habitude de s'entendre annoncer les victoires lointaines. Les courses, comme d'ailleurs tous les jeux, ont pour effet sinon pour but, d'entretenir l'apolitisme et l'indifférence. Indifférence réelle ou nourrie par la peur: le cirque offrait dans le grand monde un sujet de conversation très apprécié parce qu'il n'était pas compromettant".

(20) j. C. Edmondson I 996 e. g. 83.

(21) C. Nicolet 1980482.

(22) J. Balsdon 1969 265; D. Potter 1996 129- 159.

(23) Ver F. Oliveira - M. F. Silva, O teatro de Aristófanes, Coimbra, 199112 ss.

¡24) Para C. Nicolet (1976) 459, a partir do séc. II emergem formas paralelas de vida colectiva, e o Circo e o Anfiteatro substituem o Forum e a Cúria; cf. J. Edmondson 1996 72: "After the decline of republican political institutions, they represented almost the only remaining opportunity for the political debate between plebs and princeps".

(25) Cf J. Balsdon 1969 249; R. Auguet 197043 ss. 
contra o Prefeito do Pretório, tomado como responsável pela carestia do abastecimento alimentar. Engrossada por uma parte dos espectadores, a manifestação dirigiu-se ao Palácio Imperial e enfrentou a guarda com sucesso, levando Cómodo a ordenar a execução do Prefeito(26).

Uma outra vertente da politização dos jogos é a da política externa. De facto, no caso do teatro literário, os seus começos estão ligados a um acto de diplomacia, se é certo ter sido a vinda de Hierão de Siracusa, aliado preferencial e convidado de honra dos Romanos nas celebrações da vitória na I Guerra Púnica, o que levou à decisão de incluir no programa a primeira representação de uma peça de teatro literário.

Com os seus grandes edifícios públicos, que se repercutiam inclusive no urbanismo de Roma e das cidades de província (fig.23: Arles; e fig.24: El Jem), a cultura do lazer tornou-se um sinal claro de superioridade civilizacional: "L'architecture constituait chez les Romains un extraordinaire moyen d'action psychologique"(27).

Em conclusão: os jogos eram um dos principais veículos da superioridade da civilização romana, uma civilização que, sem a tradição sabática judaico-cristã e semítica, enfrentava o lazer com pragmatismo, integrando-o de forma dinâmica no seu viver cívico e religioso e no quotidiano. 


\section{BIBLIOGRAFIA SUMÁRIA}

R. AUGUET (1970). Cruauté et civilisation: les jeux romains, Paris, Flammarion.

J. P. V. D. BALSDON (1969). Life and Leisure in Ancient Rome, Toronto, The Bodley Head.

T. D. BARNES (1996). "Christians and the Theater", in: Roman Theater and Society, ed. W. J. SLATER, The University of Michigan Press, p. 161 - 180.

S. BARTHÉLEMY — D. GOUREVITCH (1975). Les loisirs des Romains, Paris, SEDES.

S. BARTSCH (1994). Actors in the audience. Theatricality and doublespeak from Nero to Hadrian, Harvard Univ. Press.

R. C. BEACHAM, (1999). Spectacle Entertainments ofEarly Impérial Rome, New Haven.

J. C. EDMONDSON (1996). "Dynamic Arenas: Gladiatorial Présentation in the City of Rome and the Construction of Roman Society", in: Roman Theater and Society, ed. W. J. SLATER, The University of Michigan Press, p.69- 112.

C. EDWARDS (1993). The Politics of Immorality in Ancient Rome, Cambridge U. P., cap.3.

J. ELSMER - J. MASTERS (1994). Réfections of Nero. Culture, History and Représentation, London, Duckworth.

G. C. FAGAN (1999). Bathing in public in the Roman World, Ann Arbor.

E. R. GEBHARD (1996). "The Theater and the City", in: Roman Theater and Society, ed. W. J. SLATER, The University of Michigan Press, p. I I 3- 127.

J.- C. GOLVIN - C. LANDES (1990). Amphithéâtres et Gladiateurs (1990). Paris, Presses du CNRS.

E. S. GRUEN (1993). Culture and National Identity in Republican Rome, London, Duckworth, cap. 5 .

J. GUILLÉN (1980). Vrbs Roma. Vida y Costumbres de los Romanos. II. La Vida Publica, Salamanca, Ed. Sigueme.

H. A. HARRIS (1972). Sport in Greece and Rome, London, Thames and Hudson.

H. W. JOHNSTON (1973). The Private Life of the Romans, New York, Cooper S. Publishers.

D. MANCIONI (1987). Giochi e Spettacoli, Roma.

C. NICOLET (1976). Le métier de citoyen dans la Rome Républicaine, Paris, Gallimard.

F. OLIVEIRA (1993). "Teatro e poder em Roma", in: As Línguas Clássicas. Investigação e Ensino, Coimbra, Faculdade de Letras, p. 121- 142.

F. OLIVEIRA (1993). "Teatro e poder na Grécia", Humanitas 45 69- 93.

F. OLIVEIRA (1993). "Aculturação do teatro em Roma", Mdthes/s 2 69- 90.

M. H. ROCHA PEREIRA (2986). Romana. Antologia da cultura latina, Coimbra, Instituto de Estudos Clássicos. 
A. PIGANIOL (1923). Recherches sur les jeux romains, Strasbourg, Faculté des Lettres.

D. POTTER (1996). "Performance, Power, and Justice in the High Empire", in: Roman Theater and Society, ed. W. J. SLATER, The University of Michigan Press, p. 129- 159.

R. TEJA (1996). Espectàculos y deportes en la Roma Antigua, Madrid.

P. VEYNE (1976). Le pain et le cirque. Sociologie historique d'un pluralisme politique, Paris, du Seuil.

P. WERNER (1997). Das Leben in Rom in alter Zeit, München, F. A. Herbig Verlagsbuchhandlung.

S. SETTIS (1993). Civiltà dei Romani. Un linguaggio comune, Milano, Electa. 


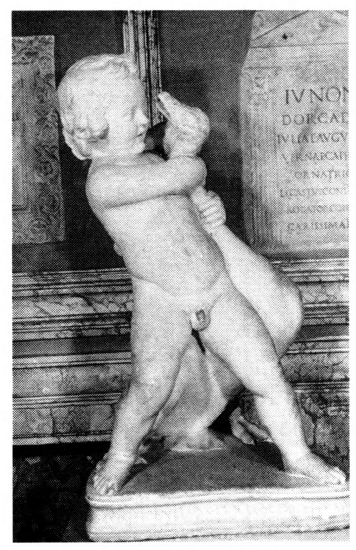

Figura I

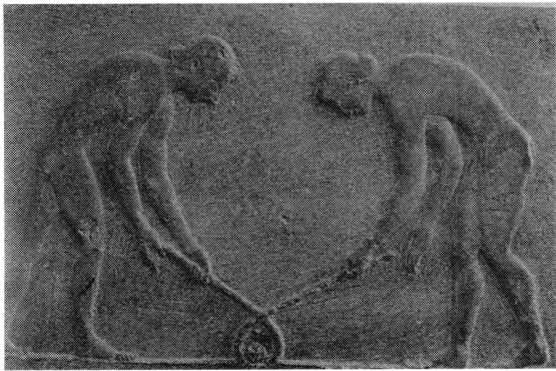

Figura 3

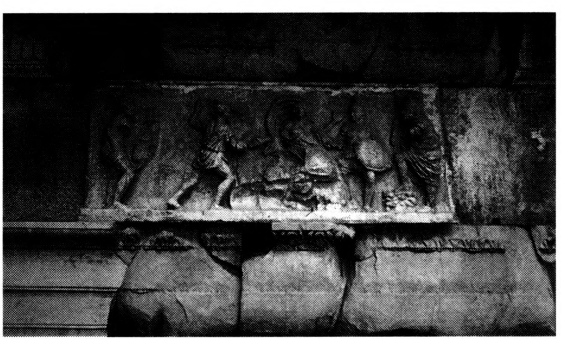

Figura 5

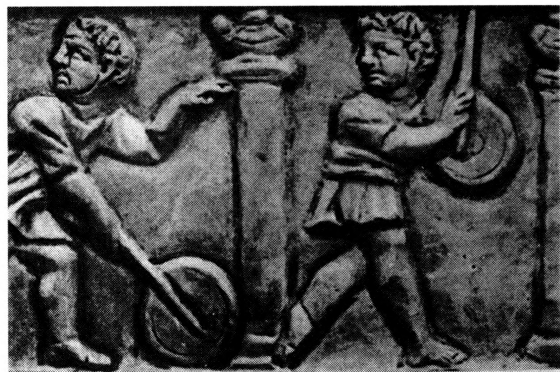

Figura 2

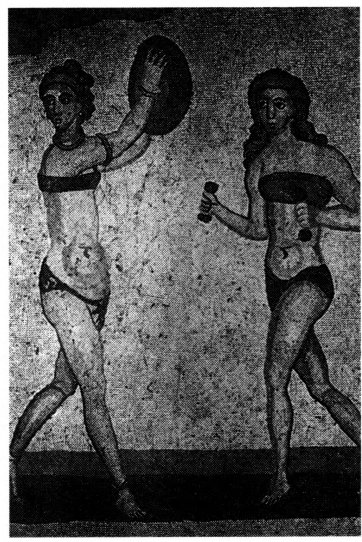

Figura 4

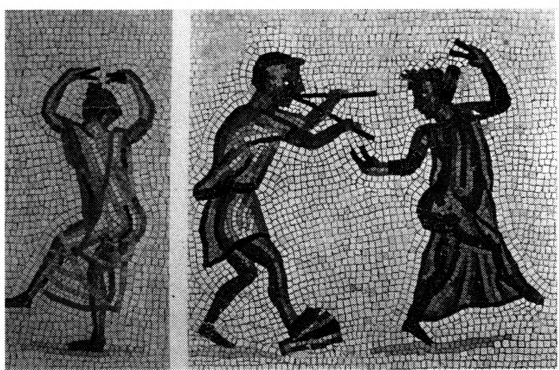

123

Figura 6 


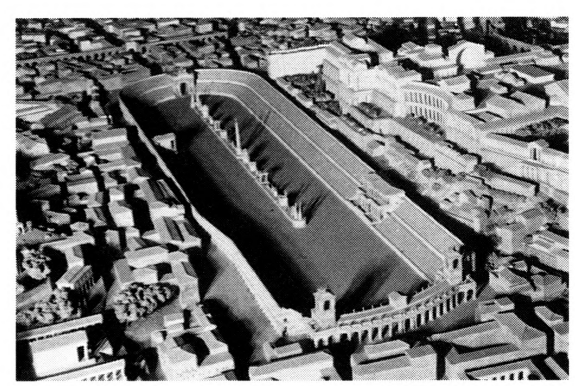

Figura 7
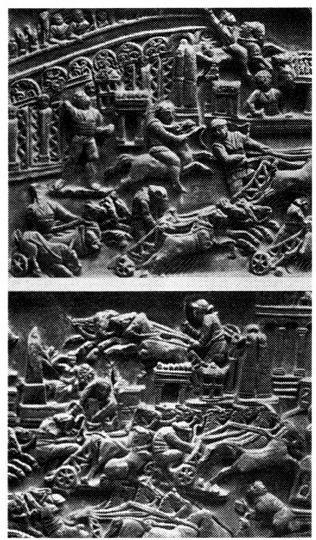

Figura 9

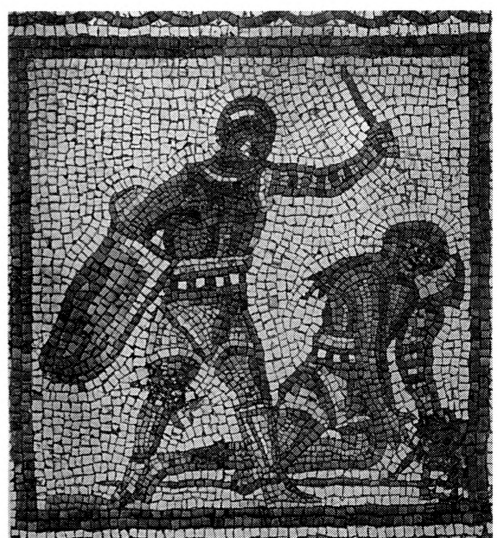

Figura II

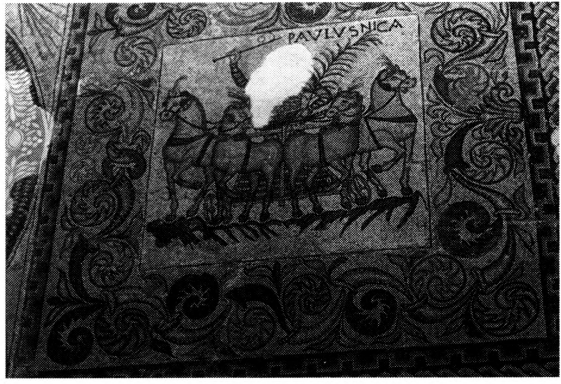

Figura 8

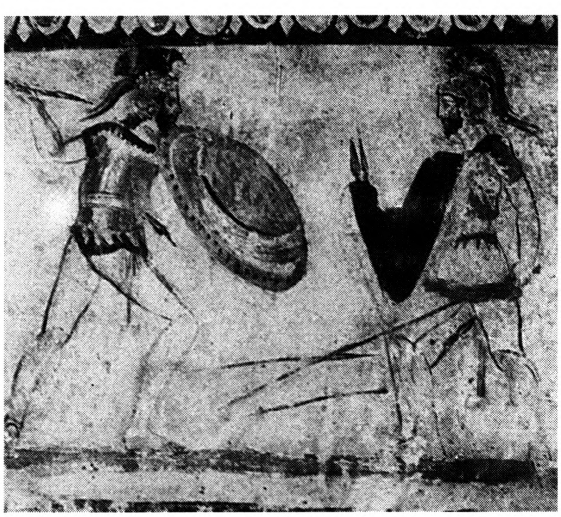

Figura 10

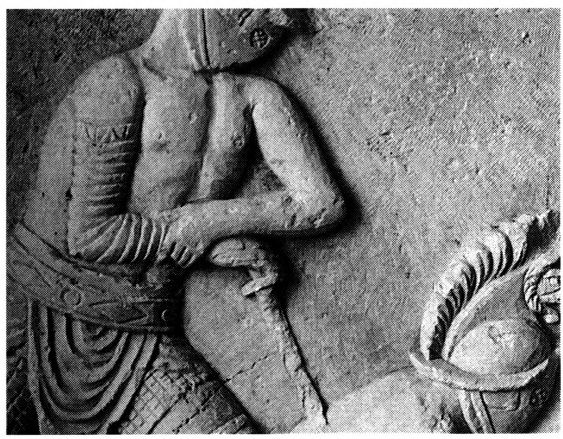

Figura 12 


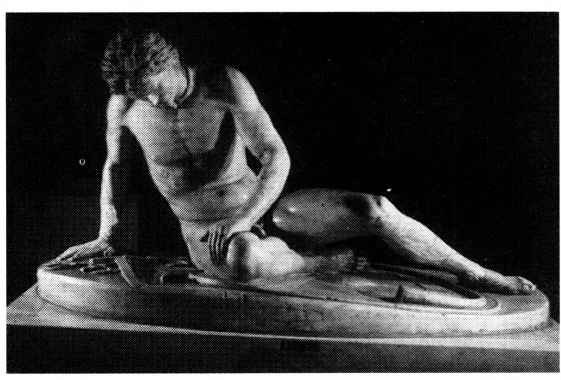

Figura 13

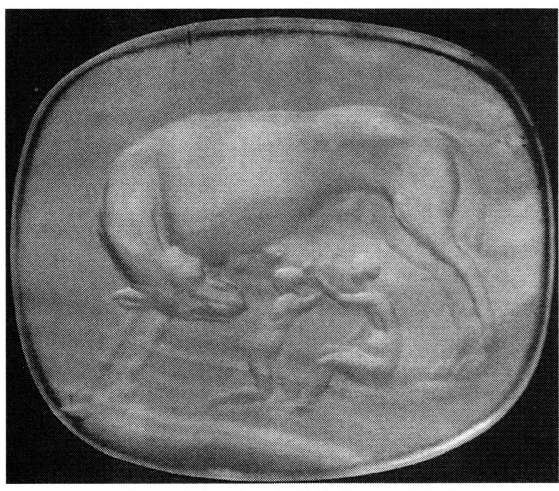

Figura 14

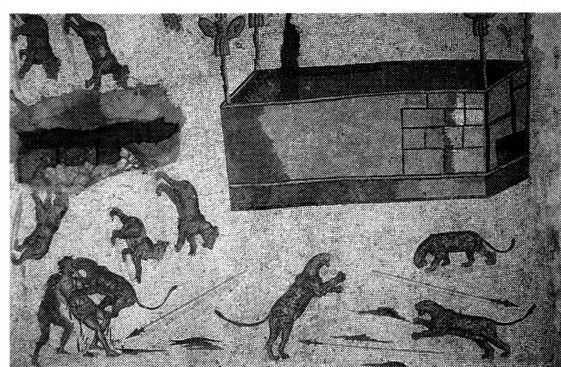

Figura 16

Figura 15

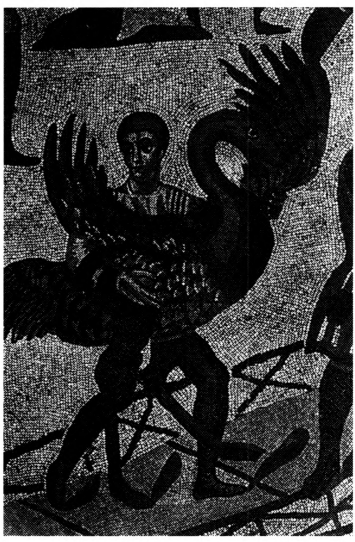

Figura 17

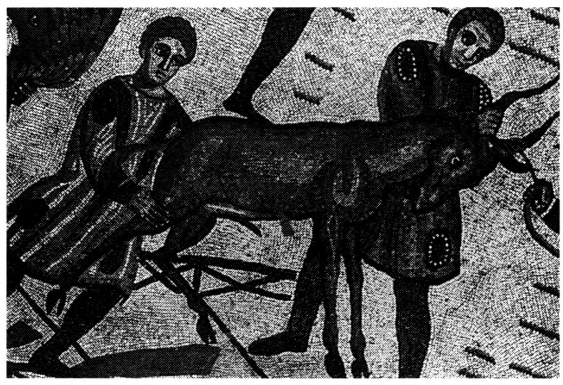

Figura 18 


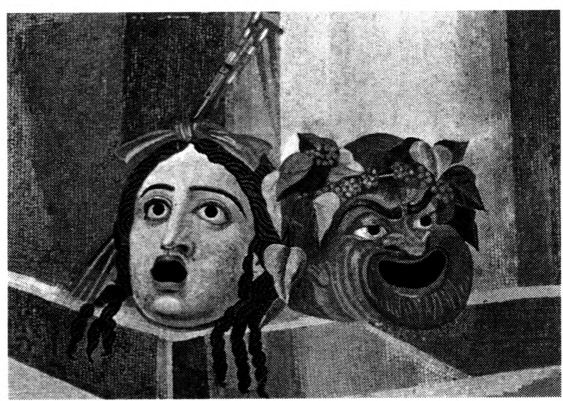

Figura 19

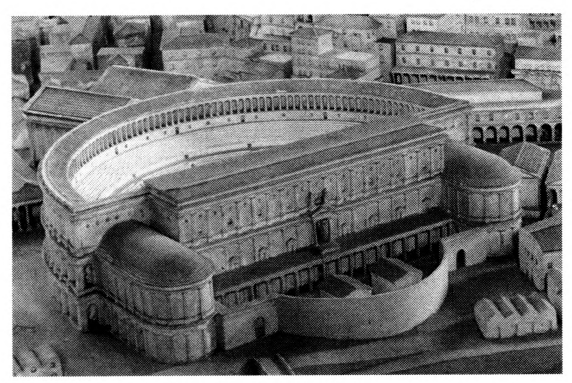

Figura 20
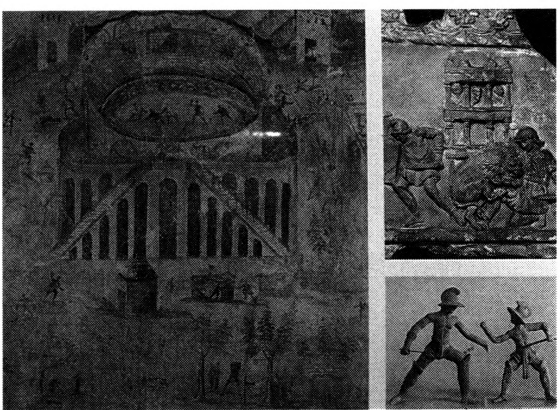

Figura 22

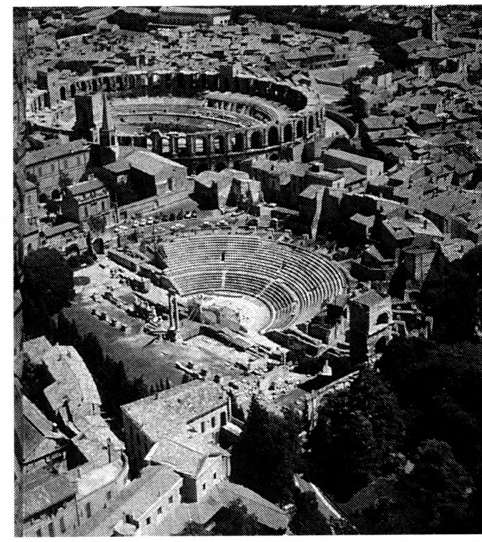

Figura 24
Figura 23

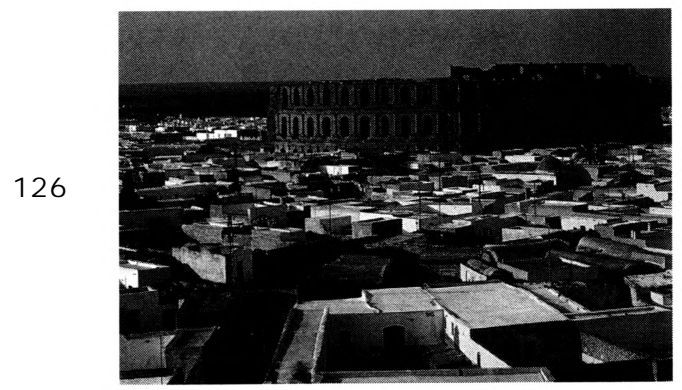

Figura 21

126

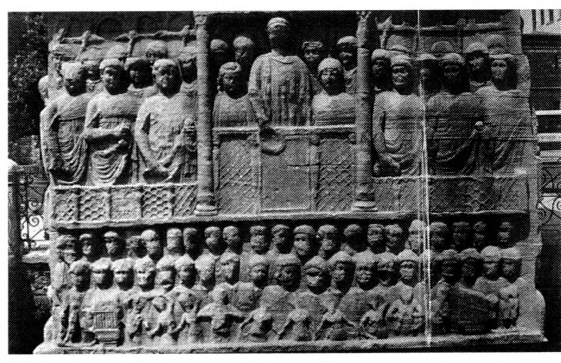

Figna 